This item was submitted to Loughborough's Research Repository by the author.

Items in Figshare are protected by copyright, with all rights reserved, unless otherwise indicated.

How can an understanding of cognitive styles enable trainee teachers to have a better understanding of differention in the classroom?

PLEASE CITE THE PUBLISHED VERSION

http://dx.doi.org/10.1007/s10671-011-9101-1

PUBLISHER

(C) Springer Verlag

VERSION

AM (Accepted Manuscript)

LICENCE

CC BY-NC-ND 4.0

REPOSITORY RECORD

Evans, Carol, and Michael J. Waring. 2019. "How Can an Understanding of Cognitive Styles Enable Trainee Teachers to Have a Better Understanding of Differention in the Classroom?". figshare.

https://hdl.handle.net/2134/11743. 
This item was submitted to Loughborough's Institutional Repository (https://dspace.lboro.ac.uk/) by the author and is made available under the following Creative Commons Licence conditions.

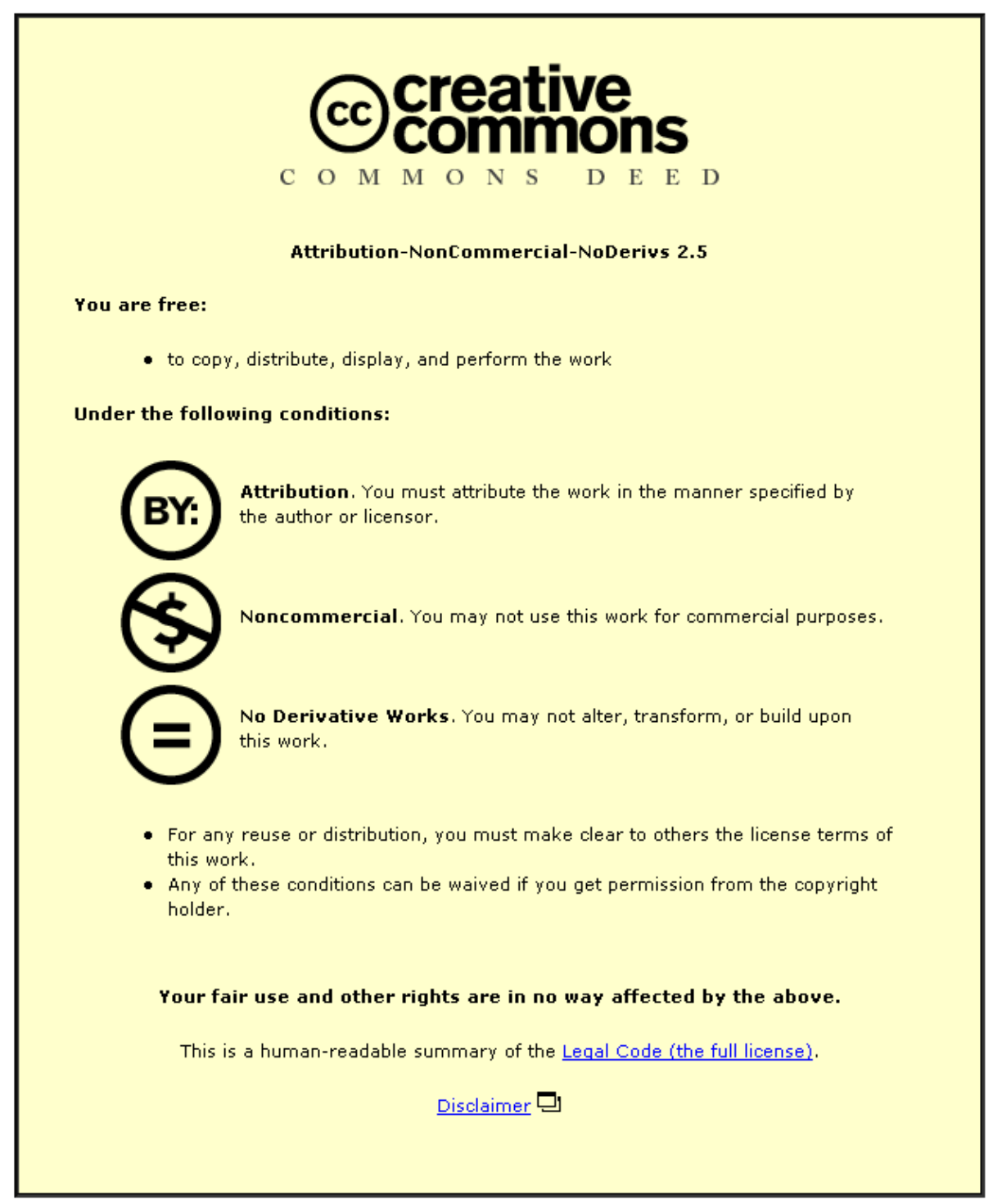

For the full text of this licence, please go to: http://creativecommons.org/licenses/by-nc-nd/2.5/ 
Educational Research for Policy and Practice 10 (3), pp149-169

\title{
How can an Understanding of Cognitive Style Enable Trainee Teachers to have a Better Understanding of Differentiation in the Classroom?
}

\author{
C. Evans and M. Waring
}

\begin{abstract}
The relationship between cognitive style and trainee teacher conceptions of differentiation was studied to develop appropriate scaffolding of their learning. 149 trainee teachers enrolled on one year postgraduate initial teacher education (ITE) programmes at two UK universities completed the Cognitive Style Index (Allinson and Hayes 1996; Hodgkinson and Sadler-Smith 2003) and a questionnaire exploring their understanding of differentiation, conceptions of learning and learning preferences. A stratified sample of these trainees was also interviewed to assess their understanding and prior knowledge of differentiation and learning styles and how they would plan for these in the classroom. Responses were coded using content analysis procedures. Cognitive style was found to impact on trainees' conceptions of differentiation; for example, trainees demonstrating higher levels of analysis and intuition had a more developed understanding of differentiation than other cognitive styles. In relation to the findings, the use of a constructivist pedagogical tool: a Personal Learning Styles Pedagogy (Evans and Waring 2009) is presented to inform the reconceptualisation of ITE programmes. In so doing, the use of this tool addresses key issues raised in recent international policy debates concerning the necessary development of ITE for twenty-first century learner needs.
\end{abstract}

Key Words: Differentiation; cognitive style; personal learning styles pedagogy; initial teacher education;

\section{Introduction}

Within a complex and rapidly evolving context of globalisation and technological change, educational systems around the World have to be attentive to the changing priorities and learning needs of students. At the core of any education system is the quality of teaching. High quality teaching has been defined as that teaching characterised by greater emphasis on teachers' values that are fundamental to good teaching; expanded teachers' roles and responsibilities of teachers that are shared collaboratively with other professionals; different career expectations and aspirations resulting from changing teacher demographics and new job opportunities; and 'personalising' learning for individual students to accommodate greater diversity in learning contexts (Gopinathan et al. 2008: 8). Consequently those policies and strategies that inform the quality of teacher preparation have never been more important, nor has the research which informs it.

This paper presents research which supports those calls for innovation and the increasing personalisation of learning for trainee teachers as part of a reconceptualisation of the way in which teachers are prepared. Trainee teachers' conceptions of differentiation will be identified along with the relationship between 
such conceptions and cognitive style in order to inform and appropriately scaffold trainee teachers' learning and understanding as part of a Personal Learning Styles Pedagogy (PLSP) (Evans and Waring 2009). We contend that being aware of individual differences in a school context and attending to these through the use of a PLSP is a fundamentally important part of the personalising of learning for trainee teachers; a view supported by Yates (2000: 347) who expounds that "Learning to cope with individual differences in student learning remains one of the more poignant issues faced by the classroom teacher".

When defining key terms, a personal learning style (PLS) involves cognitive (thinking and knowing), motivational and affective (mood, feelings) and physiological behaviours and is associated with preferred working environments, approaches to studying and learning processes. Cognitive styles refer specifically to an individual's habitual or typical way of perceiving, remember, thinking and problem solving. "Cognitive style is a person's preferred way of gathering, processing, and evaluating information... Learning style is ... a subcategory of cognitive style. It refers to the organizing and processing of information which leads to changes in knowledge and skill" (Hayes \& Allinson 1998:2).

The Individual Learning Differences (ILDs) literature is wide reaching encompassing a vast number of inter-related constructs. A search of the ERIC data base (1980-2011) identifies over 4,600 articles discussing different aspects of ILDs such as personality; gender; culture; ethnicity; age; socio-economic background; intelligence; language and motor skills, learner engagement; prior knowledge, along with a strong focus on cognitive processing and overall learning preferences in addition to affective elements: motivation, self esteem; attributions for success and failure. Within the territory of ILDs, individual personal learning styles are centrally located and have an impact on an individual's capacity to learn by enabling them to access and make sense of learning. Within this paper, our focus is primarily on cognitive styles (specifically analysis and intuition) as components of a personal learning style, as well as acknowledging that cognitive styles may interact with other ILD components.

This paper will briefly acknowledge policy developments and identify a unifying key focus for teacher education programmes globally; outline a definition of differentiation; identify the relationship between trainee teacher analysis and intuition cognitive styles and relative conceptions of differentiation. In relation to the study findings, a PLSP will be outlined and used to demonstrate how it assists in enhancing an understanding and development of style flexibility. In addition, we will demonstrate the relevance of the PLSP constructivist approach to the design of ITE programmes.

\subsection{Curriculum demands and associated educational policy}

The importance of accommodating the diverse needs of learners in the pursuit of inclusivity to enable better outcomes for all, is a global educational issue. The need to cater to "differentiated learners who may require different approaches to help them realise their full potential academically or otherwise" is evident in policy documentation (NIE 2010: 11). Embedding 'personalised learning' and 'learning how to learn' in the curriculum has and continues to be a fundamental part of English 
educational policy around 'Every Child Matters' (DfES 2004, 2006, 2007a, 2007b, DCSF 2009a, 2009b; DFE 2010). This is not confined to an English context, it is part of the wave of international attention on the processes of learning such as that evidenced in 'No Child Left Behind' in the USA (U.S. Dept for Education 2002) and 'Teach Less, Learn More' in Singapore (MOE 2005); 'New Learning' in Australia (ACDE 2001, 2004). While there may be variation in the particular emphasis and priorities associated with different teacher education programmes around the World (Wang et al.2003), one vital dimension that should dominate and unify all of them is the focus on how to learn, coupled with an understanding of the individual learning needs of students (Claxton 2007; James and McCormick 2009). Whilst the emphasis on attending to individual needs is evident in policy, it is the translation of this into practice that presents the greatest challenge (Evans and Kozhevnikov 2011; Pedrosa and da Silva Lopez 2011). The widespread call for consideration of new integrative pedagogies should not preclude existing pedagogies; it is the fusion of approaches that needs to be considered and this appears to be lost within policy debates.

Understanding how best to accommodate individual learning needs could not be more important given the impact of "knowledge-driven economies, rapid information exchanges and fast-moving communication technologies" on global educational systems (NIE 2009: 2). The need to revisit the nature of ITE and how teachers can best nurture the whole child' is highlighted in many policy developments such as that of Singapore's NIE's (2009) TE 21 - A Teacher Education Model for the $21^{\text {st }}$ Century. The more personalised approach to teaching as highlighted in the NIE framework is also indicative of changes occurring across twenty three countries within the Asia-Pacific region in relation to the need to "prepare radically new types of teachers" (IRA 2008: 3), in what can be seen as more constructivist approaches to teaching (Loyens and Gijbels 2008). Within such new learning environments, teachers will need to take on a variety of roles acting as mediators and knowledge brokers to scaffold learning appropriately to enable learners to take more responsibility for their own learning as well as address different notions of what is it to be a teaching professional (Lim et al 2009). In addition to the need for teachers to take on various and different roles, Newby (2005) argues that teaching learners skills of adaptability will be central in order to prepare individuals to be able to take on a variety of occupations within their lifespan.

Within the new learning landscape, we would argue that a key role for teachers will be in teaching learners how to navigate the vast amounts of knowledge and information involving (i) how to critically analyse sources (ii) how to synthesize such swathes of information; (iii) how to make use of this information, (iv) how to store and retrieve information (v) how to be selective in the use and storage of information. As summarised by Newby (2005: 298) "Learners will be taught how to discover things, make sense of them, package them in different ways, and put knowledge to use in a wider variety of forms and for more and more diverse functions." How teachers are prepared to provide for the effective education of learners within a changed educational landscape, with a different emphasis on particular skills, will require the provision of a specific pedagogy for creating inclusive classrooms (IRA 2008). Central to this, is the need to discuss with teachers' and learners their preexisting beliefs about learning as well as ensuring alignment between curriculum goals and the nature of assessment (Biggs 2001). 
In this increasingly personalised learning context, trainee teachers have to understand 'how to learn', to think critically and creatively as they reflect on their teaching, as well as that of others in order to develop it. They also have to be theoretically informed and aware of individual learning differences (ILDs) to enable them to involve each and every learner in the co-construction of their knowledge. By trainee teachers explicitly acknowledging their approaches to learning and teaching, as well as being aware of their cognitive styles, they will begin to put themselves in a position to be able to question and develop their approach (and that of others) towards learning and teaching (Rosenfeld \& Rosenfeld 2008). Such an approach would fit with the call for ITE curricular to focus more on what beginning teachers need to know (Kosnick and Beck 2009).

\subsection{Defining Differentiation}

In its widest sense, differentiation has been defined as "a philosophy of teaching purporting that students learn best when their teachers' effectively address variance in students' readiness levels, interests, and learning preferences" (Tomlinson 2005: 263). According to the Centre for Comprehensive Reform and Improvement (2007:1), "differentiation is modified instruction that helps students with diverse academic needs and learning styles master the same academic content".

In this paper, differentiation is defined as a central inclusive concept integral to a teacher's thinking, learning design and delivery. It involves the proactive creation of related learning activities that accommodate variances in the interest, readiness and learning profiles of all learners (and the teacher), allowing them to access the learning activity and work towards achieving the intended learning outcomes. Furthermore, differentiation in the context of cognitive styles is not necessarily about matching the needs of the learner's styles, it is about creating challenge and supporting the learner in his/her development of strategies to cope in learning situations that are not always comfortable. This involves varying both the materials learners use and the way students interact with them (Tomlinson 2000). Differentiation does not mean teaching students one by one but it does require an understanding of student strengths and current academic needs (CCSRI 2007).

Even though the ability to effectively differentiate instruction within the classroom so as to cater for ILDs may be considered an essential ingredient of good teaching, there remains considerable confusion and a lack of consensus over what differentiation of learning actually involves in a teaching context (Evans and Waring 2008). Too often differentiation is narrowly perceived as a reactive response to an individual experiencing difficulty, rather than as an inclusive concept applicable to all learners (O'Brien 2000). Such an inclusive concept of differentiation should acknowledge student and teacher differences in learning (Evans and Waring 2007). All too frequently the literature is reductionist in its presentation of differentiation concentrating narrowly on differentiating by task-outcome and by support, while at the same time failing to place differentiation at the centre of the planning process. Consequently, differentiation is too often viewed as an 'add on' rather than a fundamental consideration of individual learning needs that should underpin lesson planning. 
We do know it is difficult for trainee teachers to differentiate the learning of pupils (Henderson 2006). One factor contributing to this is that many trainees in their role as a trainee teacher observing other teachers and as pupils themselves, will be drawing on observations and experiences of limited or inadequate examples of differentiation practices in a school and university context. This is exacerbated by a lack of clarity which practicing teachers may have regarding what differentiation is and how to achieve it (Babbage et al.1999; O'Brien and Guiney 2001; Pettig 2000; Westwood 2005). O'Brien (2000) argues that four interacting elements should be taken into account when planning effectively for differentiation: pedagogical, emotional, cognitive and social; often these are overlooked (Oaksford \& Jones 2001).

To assist trainee teachers in their understanding of differentiation, Campbell et al. (2003) have provided a useful framework that encourages trainee teachers to consider how they are consistently effective in: (i) the application of different activities; (ii) across subject areas; (ii) relation to differences in pupils' background factors (differential teacher effectiveness with children of different ages, ability, gender, socio-economic background; ethnicity etc); (iv) differences in pupils' personal characteristics; (v) Differentially effective in relation to students' cognitive and learning styles, motivation, self-esteem, cultural and organizational contexts. On an individual and whole school level, consideration as to why some teachers are more effective with certain students in certain contexts is important for self and organisational learning. The key question and issue here, therefore becomes 'at what point in the trainees' development are they able to take on these issues and fundamentally, can they afford not to?'

Developing this line of questioning, a consideration of the specific skills required to enable effective differentiation in practice is important. With this endeavour in mind, Carolan and Guinn (2007: 46) have identified four characteristics of effective differentiation in practice. These include (1) personalised scaffolding to support learners in bridging the gap between whats/he can do and what s/he needs to do to complete the task; (ii) using flexible means to reach defined ends by offering multiple paths to reach defined goals; (iii) 'mining subject area expertise' by using multiple ways to navigate subject knowledge by understanding the processes of learning involved in the specific subject area; (iv) by creating caring classrooms that acknowledge and value the unique attributes of learners.

\subsection{Cognitive styles and teacher education}

Cognitive styles are perceived as higher order constructs/heuristics and represent the consistently different ways in which individuals organise and process information (Messick 1984). It is important to acknowledge that there are many different cognitive style constructs measuring similar, as well as different aspects of style (Riding 2005). An individual may use a number of cognitive styles as part of their personal leaning style (PLS). This may involve a number of different levels, ranging from the simple perceptual level (i.e. how one processes individual preferences), to decision making styles and decision making behaviour which will impact differentially on the choice of strategies adopted in particular learning situations. In this way, cognitive styles influence the ability of the individual to adopt 
flexible learning styles as part of an overall PLS. Increasingly, the traditional view that cognitive styles are bipolar; non-pejorative; non-evaluative and not readily changed (Messick 1996), is being challenged (Evans and Waring 2006, 2008, 2011; Hodgkinson and Sadler-Smith 2003).

There is strong evidence to suggest that when instruction is focused on enhancing individual understanding of one's own style profile there can be benefits to the learner in relation to developing self-regulatory skills and enhancing performance in the classroom through increased sensitivity to individual learning differences (Coffield, Moseley, Hall and Ecclestone 2004; Dunn, Griggs, Olson, Beasley, and Gorman 1995; Evans and Waring 2006, 2007, 2008, 2009; Heffler 2001; Lawrence 1997; Nielson 2008; Rosenfeld and Rosenfeld 2008; Zhang and Sternberg 2009). In this way, cognitive styles as part of a personal learning styles pedagogy (PLSP) may act as an important bridge to enable teachers to be more aware of why some learners find processing certain types of information more difficult than others (Yates 2000). The challenge for those in teacher education is to ensure an appropriate balance between the need to teach trainee teachers about the volume of domain specific frameworks and disciplinary insights, and fostering the development of skills that will enable the trainee teacher to become 'knowledgeable workers' and 'lifelong learners' (Evans and Waring 2009).

In the past, pertinent questions have been asked regarding the reliability, validity and uncritical use of certain instruments employed in cognitive styles research (Abrams 2005; Coffield et al. 2004; Hastings and Jenkins 2005; NERF 20045; NSIN 2005; Sharp, Bowker, and Byrne 2008; Stringer 2005). However, major advances in the field of cognitive styles demonstrating relevance, rigour and impact in a variety of contexts now makes such questions mute. Such work includes that applied successfully within educational settings (Evans and Waring 2006, 2009; Kozhevnikov 2007; Zhang and Sternberg 2006, 2009).

In this study, Hodgkinson and Sadler-Smith's (2003) modified version of Allinson \& Hayes (1996) Cognitive Styles Index has been employed to establish the cognitive styles of the trainee teachers. In this model, analysis and intuition are reconfigured as separate unipolar scales rather than a unidimensional model with analysis and intuition at opposite ends of a bipolar scale. This version of the Cognitive Styles Index suggests that individuals have the capacity to use both analytic and intuitive thought supporting the multidimensional nature of style underpinned by Epstein's (1994, 2004) Cognitive Experiential Self Theory (CEST) as advocated by Sadler-Smith (2008). In this context, analysis relates to reflectivity, rational, sequential and logical thinking. Intuition represents impulsivity, creativity and thinking on one's feet. The model has potential in initial teacher education (ITE) contexts as part of educating and developing metacognitive awareness amongst trainees. It is essential that trainees are informed and aware of how to develop metacognitive awareness and the importance of analytic and intuitive processing; the development of one without the other would make for an impoverished education. In teaching, the ability to use both analysis and intuition appropriately is vital. The literature has identified that trainees who are low in analysis and intuition may be considered to have an 'impoverished style' in relation to being able to teach as effectively as those with higher levels of analysis and intuition (Evans and Waring 2006, 2008). In teaching, the key question lies in whether individuals are able to vary 
their styles according to the needs of the situation; this would demand high levels of intuition to effectively read situations, as well as confidence and ability in being able to adapt in varied and changing circumstances.

If educational institutions are deemed to favour and promote certain cognitive styles (Kirton and DeCiantis 1986), to what extent have and will the trainee teachers be helped to develop cognitive flexibility? We know that certain cultures in institutions and countries may favour certain types of processing over others, for example, it could be argued that the highly analytic processing mode favoured in English schools and universities today, may well lead to students coming to ITE courses with better developed analytic than intuitive tools (Evans and Waring 2009). At the same time, the question of the extent to which cognitive style is both innate and learned becomes pertinent.

A PLSP approach can be employed to assist trainees in making sense of their own conceptions of learning, as well as assisting them in their understanding of different ways of processing information so as to enable them to be more attuned to planning effectively for ILDs in their own lessons. A PLSP incorporates a number of key aspects including: the centrality of the learner in the whole process; the unique starting point of each learner; choice for learners; explicit guidance; concrete and appropriate exemplars to contextualise learning events; observation of different ways of seeing and doing; transference and reinforcement of ideas to new contexts. It is vital that trainee teachers are exposed to a variety of such learning experiences in order for them to be able to rehearse, experiment, play, act and reflect on ideas and approaches within their own contexts (school- and university-based), and importantly augment those usually impoverished learning experiences and models they have previously had and observed (Grossman et al. 2009; Mutton et al. 2009).

\section{Method}

In this study we were seeking to ascertain the cognitive styles of the trainees in order to consider whether the trainees' cognitive styles profiles impacted on their conceptions of differentiation. A fundamental aspect of this study was to also consider how an understanding of styles as part of a personal learning styles pedagogy approach could help trainees to understand key principles underpinning differentiation to assist them in addressing the individual learning needs of their students.

One hundred and forty nine trainee teachers (males $=62$; females $=87$ ) aged between 21 and 55 years (mean 24 yrs) enrolled on a one year Postgraduate Certificate in Education (PGCE) programme participated in the study. The trainee teachers involved were studying at 2 different UK universities: University $\mathrm{X}(\mathrm{N}=69$; males $=29$; females $=40)$ and University $(\mathrm{N}=80$; males $=33$; females $=47)$. The sample from University $\mathrm{X}$ included trainees across a number of different subject specialisms (English; Geography; History; Mathematics; Modern Foreign Languages; Music; Physical Education; Religious Education; Science). Trainees from University $\mathrm{Y}$ were all recruited from the Physical Education ITE programme. The samples in both instances were opportunistic ones. Following each university's ethical procedures, all trainees voluntarily agreed to be involved in the project and were able to withdraw at any time. A fundamental principle underpinning this study was that the 
trainee teachers should be fully involved in all aspects of it and not used as 'research objects'.

To address the key aims of the study, all trainees completed the Cognitive Style Index (CSI) (Allinson and Hayes, 1996) at the beginning of their course. This measure is one of the most reliable and valid measures, possessing good psychometric credentials (Coffield et.al. 2004), as well as being relatively straight-forward to administer. Following instruction on cognitive styles, which involved lectures and follow up sessions to exemplify areas where the trainees wanted greater clarification, all trainees also completed a questionnaire asking them about their conceptions of differentiation as well as their learning and teaching preferences. The questionnaire included three sections: Section A included open-ended questions on trainees perceptions of learning and differentiation. These responses were subject to content analysis procedures, initially conducted independently by two researchers and then triangulated. Sections B and C of the questionnaire presented trainee teachers with a number of statements which they were asked to rank on a 5 point scale the degree to which they strongly agreed (1) or strongly disagreed (5) with the statements on ways of working and learning preferences; these responses were analysed using SPSS. Section B questions focused on trainees general learning preferences and ways of working and Section $\mathrm{C}$ questions considered trainees teaching design preferences in specific situations. Considerable time was spent working with all trainees throughout the year to explain and exemplify the results in relation to their understanding and needs as they learnt to teach. Using stratified and random sampling procedures trainees with differing style profiles were invited to be part of focus group interviews to explore issues raised in the teaching sessions and questionnaire responses $(n=40)$. The transcriptions were analysed using content analysis procedures (de Vaus 2002).

\section{Results and discussion}

\subsection{Trainee teacher's cognitive styles and conceptions of differentiation}

The CSI scores were calculated using a revised scoring method advocated by Hodgkinson and Sadler-Smith (2003) with analysis and intuition identified as coexisting complementary modes of information processing. The original test comprises 38 statements scored in a trichotomous scale (true; uncertain; false). Using the revised scoring method both analytic and intuitive items are scored positively on two separate scales: true $=2$; uncertain $=1$ and false $=0$ ). Thus, 21 statements measure analysis, resulting in a maximum score of 42 and a minimum of $0 ; 17$ statements measure intuition, giving a maximum score of 34 and minimum of 0 . Intuition scores were later recalculated out of 42 to enable direct comparison with analysis scores. Using mean scores for analysis (28.4) and intuition (22.35) dimensions, it was possible to divide the data into four groupings: (1) High AnalysisLow Intuition; (2) High Analysis-High Intuition; (3) Low Analysis-Low Intuition and (4) Low Analysis-High Intuition.

\subsection{Analysis and Intuition Scores}


The analysis mean score for the whole data set was $28.4(\mathrm{SD}=7.7)$. There were statistically significant differences between analysis scores of the two universities in question $(\mathrm{t}=-2.078, \mathrm{df}=121.09 ; \mathrm{p}=.40)$, although the size of the difference as measured by partial eta squared was small and statistical significance borderline. Mean analysis scores for University $\mathrm{X}=27 ; \mathrm{N}=69$; $\mathrm{SD}=8.8$; University $\mathrm{Y}$, mean analysis $=29.65, \mathrm{~N}=80, \mathrm{SD}=6.3$. There was no statistically significant difference between intuition scores at the 2 universities: Overall mean $=22.4$ (University $\mathrm{X}$ mean $=23.4, \mathrm{~N}=69 ; \mathrm{SD}=8.3$; University $\mathrm{Y}=21.42 ; \mathrm{N}=80 ; \mathrm{SD}=7.8$ ). No statistically significant differences were found between male and female analysis and intuition scores.

Analysis scores were higher than intuition ones. The distribution of individuals across the 4 styles groupings: [Style 1: high analysis, low intuition; Style 2: high analysis, high intuition; Style 3: low analysis, low intuition and Style 4: low analysis, high intuition] was similar at both universities with majority of trainees falling into group 1 and secondly, group 4 . Style 1 comprised $42 \%$ of the cohort; style 2 (14\%); style $3(15 \%)$ and style $4(28 \%)$.

\subsection{Differences in learning preferences}

A one-way between-groups analysis of variance was used to ascertain any statistically significant patterns within the data in relation to differences in learning preference; these are summarised in Tables 1 and 2.

\section{INSERT TABLES 1 and 2 HERE}

The $\mathrm{F}$ values and significance can be seen in Tables 1 and 2. Particularly large effect sizes can be found in relation to two items. Firstly, in relation to item B7: "I like to follow a clear set of logical procedures, analysing each step as I go," significant differences were identified between Style 1 and Styles 2 and 4 with Style 1 students preferring a more analytic approach as would be expected from their styles profile (Allinson and Hayes 1996). Secondly, in relation to item B10: "In a new situation I like to take the initiative, being able to step in and direct things where necessary," significant differences were found between Styles 1 and 2 and 4 with Style 1 being less likely to want to take the initiative; between Styles 2 and 3 (3 less likely to take initiative compared to styles 2) and between Styles 3 and 4 (3 less likely to take initiative compared to 4); again, such results fit with the expectations of such style profiles (Epstein 2004; Hayes and Allinson 1998; Hodgkinson and Sadler-Smith 2003; Riding and Rayner 1998)

Style 1 trainees (high analysis, low intuition) were most likely to like logical, sequential learning situations, to like following rules, prefer weighing up all evidence before arriving at a conclusion and to require clear outlines of work to be covered. The trainees were less happy to multi-task, less keen on trying out new ideas, less likely to take the initiative in new situations, less likely to arrive at decisions quickly and less likely to like unstructured learning situations. 
Style 2 trainees (high analysis, high intuition) exhibited a preference for inventing and trying out new ideas; liked taking the initiative, liked directing and leading. They were less likely to follow procedures.

Style 3 trainees (low analysis, low intuition) were less keen on multi-tasking, less likely to take the initiative, less likely to scan information quickly and come to quick decisions and disliked unstructured learning situations.

Style 4 trainees (low analysis, high intuition) as might be expected, were most happy to multi-task, try out new ideas, take risks, take the initiative in new situations, make decisions quickly, scan and come to conclusions most quickly. In addition, they most favoured informal working environments and less structured ones and found it easier to move from one project to another.

One of the issue here, is the extent to which learning style preferences influence trainees' styles of teaching. Zhang and Sternberg (2006) argue that students and teachers have preferred styles and that their styles matter significantly in their learning and teaching behaviours respectively. However, whether teachers actually teach in one specific style has been questioned by Evans (2004). In addition, the impact of the matching of styles of teaching to styles of learning on performance has produced very mixed results (Evans and Waring 2009). An interesting conclusion reached by Zhang (in press) is that although teaching styles promoting the holistic development of a learner may be more popular with students, such teaching styles do not necessarily lead to better student performance; the nature of assessment is implicated here. This leads back to comments made earlier, that if one is implementing new aspects of curriculum design, alignment between all elements including assessment is vital (Biggs 2001).

A second issue is in training teachers how to accommodate the varied needs of learners within their classrooms. Raising awareness of different approaches to styles through the judicious use of styles instruments to provide a lexicon of learning that trainees can use to consider their own ways of planning and delivering content along with a consideration of ways of interacting with students in the learning process can be helpful in this respect.

\subsection{Contextual issues}

Whilst it is possible to identify learning preferences common to specific styles across the two Universities, it was also evident that subject, immediate context and institution had an impact on trainee learning preferences. Further work is required to consider more fully the interaction of cognitive style with other ILDs such as gender and culture. Interaction effects between analysis and intuition, cognitive styles and learning preferences have been identified (Evans 2004; Evans and Waring 2006). It is also possible to posit that different organisations and cultures may favour the development of certain cognitive styles over others (Hayes and Allinson, 1998).

All trainee teachers in this study placed high emphasis on 'active' learning (trying out ideas/practical work, although this was in much greater emphasis at University Y relating to PE subject focus of the groups involved (mean response at $\mathrm{Y}$ 
$=40 \%$; equivalent at $\mathrm{X}=28 \%$ ). Consolidation of learning through the discussion of ideas with peers was dominant at both universities. Consolidation of learning involving rehearsing, memorisation, re-writing was important to Style 1s at both universities. Visual learning was a common response amongst all trainees (mean $\mathrm{X}=$ 34\%; Y $=34 \%$ ), but especially Style 2 at University Y and style 4 at University X. Over a quarter of the Style 2 trainees across both universities cited 'interest' as a key factor influencing their learning, unlike the other three style groupings who hardly mentioned this at all. Style 3 (Low A and Low I), as might be expected, were the most passive learners across both institutions.

Key differences between the two university groups included the greater preference of University $\mathrm{X}$ trainees compared to those at University $\mathrm{Y}$ for lecture format, individual and group work (preference for working alone when first tackling a task followed up with group work) and self-reliance (relying on their own reading and writing and re-writing information). By way of contrast, group work, active learning, visual, observation, consolidation and writing notes were the favoured options for University Y trainees.

\subsection{Style differences / similarities regarding conceptions of differentiation}

When considering responses to questions about their own learning and conceptions of differentiation, similarities and differences were evident between trainees from the two institutions. In part this is testament to the influence of contextual factors in addition to a number of other potential layers (e.g. gender, intelligence, culture, personality, prior learning experiences) that impact on individual learning differences, cognitive style merely being one of these.

\subsection{Understanding of differentiation}

An impoverished understanding of differentiation was evident amongst all trainees. While $25 \%$ of trainees acknowledged differentiation as 'learning in different ways', they found it difficult to articulate what this meant in practice. Most trainees considered differentiation to be a reactive strategy to cope with the 'less able' pupils in a class. However, Style 1 (HA/LI) trainees at University $\mathrm{X}$ consistently demonstrated an awareness of the need to 'cater for all pupils', as well as a familiarity with a limited number of learning styles (e.g. VAK). Similar familiarity with learning styles models was demonstrated by Style 2 (HA/HI) trainees at both universities. However, Style 3s (LA/LI) at both institutions remained predominantly unaware of learning styles. Style $1(32 \%)$ and style $2(20 \%)$ trainees at both universities highlighted variation in teaching style as a component of differentiation. Style 2 along with style 4 (LA/HI) emphasised the need to employ different teaching methods in the classroom in order to differentiate learning. Minimal awareness of special educational needs and ethnicity was evident in relation to all styles, these areas being rarely commented upon.

From the focus group interviews, styles differences were apparent in the trainees' awareness of differentiation and their attitudes to developing their practice. Style 1 trainees felt they needed to know more about their own learning if they were to be more effective in attending to the differing learning needs of their students. Over a third of the trainees felt they could apply the ideas they had learnt as a consequence 
of the project more easily. These trainees were most able to articulate how they would embed a cognitive styles approach into their teaching.

Style 2 trainees demonstrated a greater awareness of the potential of cognitive styles to their teaching from the outset. Eighty percent of the trainees found the project useful in helping them to develop more varied questioning techniques. They had a very good metacognitive awareness of their own learning. They knew less about how to group students effectively for specific tasks.

Style 3 trainees demonstrated poorer awareness of their own learning and they were less positive about the training they received on styles (40\% found this beneficial) as many could not see the relevance of styles research to classroom practice. They were, however, keen to learn how to use groupings effectively within the classroom.

Style 4 trainees were mainly very positive about the cognitive styles work, however, they wanted more interaction in discussion sessions. This group were most aware of special educational needs issues of all four groups. They were aware of the need to vary styles of teaching but also wanted more explicit guidance on how to do this and more training in how to work effectively with groups.

\subsection{Planning for differentiation}

Trainees had limited awareness of how differentiation would manifest itself in the classroom. There was a lack of awareness of the use of alternative ways of organising pupils in the classroom. However, the need to be able to cater for high ability pupils was identified as a key focus by the trainee teachers irrespective of university. The importance of assessing the prior knowledge of pupils was raised by $30 \%$ of trainees from University Y and $20 \%$ from University X, although very few Style 3 trainees across each of the institutions raised this. Style 2 trainees across both institutions were more aware than all other style groupings of the need to vary teaching style and to provide challenge in learning. Style 3 trainees were least likely to refer to different learning styles although they were most likely to talk about the need to vary tasks.

Statistically significant differences between certain styles, particularly Styles 1 and 4, regarding their perceived learning needs were evident. Commenting on the items in Table 2, with the largest effect sizes, certain needs are apparent. Style 1 trainees reported being most happy with clear and logical procedures whereas Style 2 and 4 trainees with higher levels of intuition preferred opportunities to take the initiative; multi-task; try out new ideas and work in unstructured learning environments. Style 3 trainees were less likely to want to multi-task or take the initiative and required more time to consider information preferring structured learning environments. It is also apparent from looking at trainee responses that cognitive style did impact on their views of differentiation and that other contextual factors were evident e.g. subject specialism and university context.

Discussions with the trainees, on the whole, indicated that they had found the PLSP approach valuable. In a previous study, Evans and Waring (2008) did find that 
trainees did adapt their approaches to learning following such an intervention. However, whether such changes are temporary or sustained is open to question. Can a relatively short-term intervention bring about significant change in trainee beliefs about learning and teaching given that some individuals are capable of greater style flexibility than others (Kozhevnikov 2007)? The longer term impact of such interventions requires further investigation (Evans and Cools 2009).

3.8 Enhancing understanding and developing style flexibility as part of a personal learning styles pedagogy (PLSP)

The questionnaire results and focus group interviews confirmed that trainees did have favoured styles and that these impacted on their ways of thinking and learning. In trying to enhance trainees' understanding of differentiation, we used a PLSP approach informed by a constructivist socio-cultural theoretical framework (Loyens and Gijbels 2008). Underpinning a personal learning styles pedagogy (PLSP) is a desire to improve the conditions for learning for all learners by acknowledging, accommodating and developing difference. In order to best enact this, trainees in addition to having a sound knowledge and understanding of the possibilities and limitations of styles research, should focus on the process of learning making explicit alternative approaches to learning situations, acknowledging and being sensitive to the differing ways in which individuals perceive and react to learning situations. The centrality of the learner is fundamental in the development and co-construction of knowledge and understanding of cognitive styles as part of a PLSP. A PLSP is not about promoting the accommodation of each learner's predominant styles in each situation. It is about adopting a central philosophy that has at its core an understanding of individual difference. There are five key interrelated areas to address to enable trainees to better understand and apply styles ideas in the classroom to facilitate differentiated instruction (Evans and Waring 2009). These are:

A. Exploration of teacher beliefs / modelling and support:

- Teachers view on learning

- Trainees preparation to increase sensitivity to learners needs

B. Careful selection and application of models to suit the needs of specific learners:

- Selection of personal learning styles models

- Inclusion of styles models

- Appropriate application of styles models

C. Creating optimal conditions for learning:

- Approach to apprenticeship in initial teacher education

- Enabling a positive learning environment

- Sensitivity to the needs of the learner

- Choices in learning

D. Student voice by having full involvement of learners in the process of learning:

- Metacognitive use of cognitive styles

- Trainees as co-designers of their learning

E. Design of learning environment: 
- Toleration of uncertainty

- Extending the learning challenge

- Accommodating different styles

- Use of technology to support learning

- Identification of types and awareness of labelling students

- Informed and responsible use of grouping to encourage development of styles.

There are a number of ways in which the use of a Personal Learning Styles Pedagogy can assist in developing trainee understandings of different ways of working so that they are able to develop their own style flexibility and that of their pupils. Detailed examination of the practical application of a PLSP within teacher education can be found in Evans and Waring (2009).

In relation to this study and confirmatory of previous findings from research on trainee teachers' cognitive style profiles (Evans and Waring 2006, 2007, 2008, 2009, 2011), the analysis scores of the trainees were higher than their intuition ones. Considering the distribution of trainee cognitive style scores, a key question has to be how to increase both analytic and intuitive capacity given that only $14 \%$ of the trainees demonstrated high levels of analysis and intuition and that $15 \%$ of trainees demonstrated relatively low levels of analysis and intuition. It is this latter group which demonstrated less awareness and understanding of how to differentiate and have also been found to be less effective in teaching in other studies we have carried out (Evans and Waring 2008, 2009).

To explore and develop style flexibility, it is possible to use a four stage model to demonstrate how cognitive styles may be developed through the use of specific interventions. Stage 1 would involve the observation of trainees in their tackling of specific learning and teaching tasks. Stage 2 would involve training and coaching in alternative teaching and learning approaches to address the learning objectives for specific learning activities. Stage 3 would involve watching the trainees apply their learning to new and different contexts to ascertain whether trainees had been able to assimilate new ideas into their teaching practice, Finally, stage 4 would focus on trainees continuing to embed new teaching approaches through further critical self and peer reflection and reinforcement activities. As part of this four stage model, trainees need to be encouraged to share and challenge their own and others' existing conceptions of learning through examination of the impact that specific cognitive styles such as intuitive and analytic (CSI) thinking may have on their own views of learning.

To facilitate trainee learning and to address the issue that many trainees may have had limited experience of varied approaches to differentiation, explicit modelling by HEIs of different approaches within the classroom is essential. For example, trainees need to be exposed to both familiar and unfamiliar ways of working in relation to all aspects of the ITE programme. Trainees need to consider how elements of instruction can be delivered in different ways to maximise learning outcomes. This may involve consideration of the benefits and limitations of different approaches to classroom design. 
By giving such structured feedback on practice, trainees can be encouraged to consider how specific lesson design features, may impact differentially on an individual's access to learning in the classroom. From a cognitive styles perspective, we particularly focused within the PLSP on issues in relation to:

(i) Volume of material:

(ii) Modes of presentation:

(iii) Pace, speed and number of transitions between activities:

(iv) Design of learning sequences (tangential vs sequential):

\author{
What are the essential concepts to be delivered? How can \\ this material be organised in different ways? \\ What is the best way to present and design information in \\ relation to the required outcomes of the task? \\ What is the impact of pace on different types of learning \\ and for different learners?
} What am I doing to encourage students to think both
creatively and rationally?

Am I using a range of question types to suit the needs of the learning objectives?

In my teaching, am I harnessing flexibility in styles (e.g. impulsive and reflective and analytic and intuitive cognitive styles)?

Am I facilitating and directing learning in appropriate ways? Am I encouraging both independence in learning as well as inter-dependence?

Am I using structure and a lack of structure in lesson design to support learning most effectively?

Am I using a variety of seating arrangements to support specific learning goals?

To what extent am I introducing choice for learners and listening to student voice?

How am I using different groupings of students to support the development of interpersonal skills?

Am I using a range of assessment options that are aligned to the learning objectives? Am I providing sufficient choice in assessment?

Furthermore, HEIs need to promote the importance of risk-taking i.e. the trialling of different teaching approaches and strategies within the classroom to facilitate learning. To consolidate understandings of alternative ways of teaching, trainees need to demonstrate how to deliver content in a variety of ways and need to research the impact of such practice on their students (TLRP 2008). Assumptions are often made about the benefits of self-reflection in developing practice. From our focus interviews with trainees, we would advocate the need for structured debriefing of trainee teaching episodes in order for trainees to develop such skills to enable them to feedback effectively to each other. Trainees did want explicit guidance in how to analyse their own teaching and that of others. Support in the form of assisting trainees to self-analyse and critique their own work and that of other teachers, needs to be a central feature of ITE programmes.

\subsection{Implications for policy}


This work is confirmatory of the fact that individual learning differences do matter (Zhang and Sternberg 2009). They affect the ways that individuals perceive and approach tasks and in this example, they impacted on trainees conceptions of differentiation. This work also highlights the importance of the consideration of contextual variables alongside ILDs in informing practice. A central question is how can this research assist trainee teachers and teacher educators to reconceptualise the way teachers should be trained? In informing policy, we would argue that attention needs to be given to the following areas:

(i) how to integrate new pedagogies with traditional ones;

(ii) the need to consider issues associated with the translation of concepts to new environments;

(iii) developing common understandings though explication of beliefs and values;

(iv) focusing on what trainees need to know including ILDs at the start of their teaching careers;

(v) explicit guidance and modelling of different approaches to teaching and learning;

(vi) involving trainees and teachers in the co-construction of knowledge about teaching and learning.

Much emphasis is currently being placed on the need to develop $21^{\text {st }}$ century teachers with "the right values, skills and knowledge to be effective practitioners who will bring about the desired outcomes of education" (NIE 2009: 2). However, we would argue that this approach fails to acknowledge the strengths of existing pedagogies; it is how the old and new are blended together that will be important especially given that many teachers see direct transmission and constructivist approaches as complementary (OECD 2009).

When introducing 'new learning environments' (NLEs), more attention needs to be focused on the process of how this can be done most effectively. The translation of constructivist learning principles into practice has proven difficult and complex due to the different interpretations of what this actually involves, including how the different elements are meshed together (Harris and Alexander 1998). Sensitivity to contextual variables is important in the translation of pedagogies to different cultural contexts. On-going coaching and support needs to be an integral element of training when introducing new ways of teaching for both teachers and trainees (TL2020RG 2006). Both trainees and teachers need opportunities to learn about and understand the complex nature of practice (Grossman et al. 2009). This is especially problematic, given the findings of the OECD (2009) TALIS report involving 23 countries and 70,000 teachers, in which $75 \%$ of teachers reported that they would receive no recognition for being more innovative in their teaching. Of note, is that teachers in most countries reported using traditional practices aimed at transmitting knowledge far more than they used student-oriented practices. Variations in use were found to be at the individual level rather than at the country or school level suggesting the need for targeted programmes to support teachers rather than whole-school or system wide interventions that have traditionally dominated educational policy (OECD 2009).

We would advocate that within an ITE curriculum more time should be devoted to discussion of trainee and teacher values and beliefs about learning along with developing knowledge and understanding of inclusive education (Gore et al. 
2007). Poplin and Rivera (2005: 28) extend this by advocating that teacher education programmes should enable teachers to emerge "committed to confronting social inequalities, skilled in teaching academic knowledge, convinced that poor and marginalized students can learn, and acquainted with teachers who can and do teach them effectively". In this article, we have argued the importance of exploring the trainees' values and beliefs about learning but this cannot be done in a vacuum, it is also needs to be conducted in schools with trainees and their teachers in order to develop a common understanding and language in relation to differentiated practice. It is not only trainees that struggle with the implementation of effective differentiated practice, many experienced teachers in schools also find differentiation difficult (Everest 2003) and they also need to see unfamiliar practices being used in practice. Furthermore, HEIs also need to consider what types of learning they are promoting?

An integral component of the PLSP is enabling time for trainees to develop their skills in noticing (Mason 2009). Common trends in ITE policy call for trainees to be spending more time in schools (DFE 2010), however, the quality of the learning experience rather than the number of hours spent in schools needs to be considered. The MOE's "Less is More" strategy (2005) could be extended to how trainee teachers are prepared for teaching. More consideration needs to be given to the best ways of supporting trainees in meaningful learning incidents and more 'approximations of practice' (Grossman et al. 2009). Trainees need instruction on how to notice and need more time on practising specific approaches with peers and teaching colleagues as well as with students. In listening to our trainees, they welcomed more input on special educational needs as well as more focused time to explore the development of interpersonal skills including how to manage different groupings of students most effectively. Many would also argue for the paring down of the ITE curriculum to focus more on what trainee teachers need to know at the start of their journey into teaching (Kosnik and Beck 2009). Supporting the findings of the teaching and Learning Research Project (TLRP 2008), we would also argue the importance of training teachers and trainees in how to analyse the impact of what they are doing in the classroom on student learning; the PLSP approaches enables such a focus on metacognitive processes.

\section{Conclusion}

This study illustrates that cognitive style is one factor affecting the decisions that trainee teachers make in their teaching. Trainees have to be cognisant of their style preferences if they are to be able to readily frame learning activities in a variety of ways. This is important in two respects: Firstly, in making learning accessible; secondly, in encouraging style flexibility in those learners they teach. It is possible to identify consistent cognitive styles biases in thinking which having been acknowledged can be explored with trainees around a PLSP and the five key interrelated areas, so as to enable them to develop more holistic practice in their teaching and enable learners to develop their analytic and intuitive capacities. Having explored conceptions, beliefs and favoured approaches to learning tasks and situations, trainee teachers need to be given as many authentic opportunities as possible to practice different approaches to differentiation so that they become a fluid part of their everyday practice. Trainee teachers need to be provided with a variety of contexts and methodologies to allow them to reflect on their preconceptions and 
refine their understandings by being given the opportunities to enact new schema that they have acquired (Younger et al. 2004; Grossman, et al. 2009). In addition, the tensions and potential conflict between those values and beliefs of the trainee teacher and the need for them to learn to teach within certain rules and routines in a school and university context, is an area that needs to be acknowledged and explored more explicitly in terms of how the trainee teacher can navigate and filter the information and requirements of school-based settings; this is not unproblematic.

A Personal Learning Styles Pedagogy along with the ways in which it can assist in enhancing our understanding and development of style flexibility has been outlined. We would argue that it is essential for ITE programmes globally to reconceptualise what beginning teachers need to know particularly in regards to an understanding of differentiation across and within contexts and the processes that are going to achieve it. It is only by doing this that they will develop and reinvigorate their ITE programmes in a way which will allow trainee teachers to truly make sense of learning and in so doing empower the learners of the $21^{\text {st }}$ century.

\section{References}

Abrams, F. (2005). Cognitive Conundrum. The Times Educational Supplement, May $20^{\text {th }} 2005$.

ACDE. (2001). New Learning: A Charter for Australian Education. Canberra: Australian Council of Deans of Education.

ACDE. (2004). New Teaching, New Learning. Canberra: Australian Council of Deans of Education.

Allinson, C. W., \& Hayes, J. (1996). The Cognitive Styles Index: a measure of intuition-analysis for organisational research. Journal of Management Studies, 33(1), 119-135.

Babbage, R., Byers, B., \& Redding, H. (1999). Approaches to Teaching and Learning: Including Pupils with Learning Difficulties. London: Fulton.

Biggs, J. B. (2001). Enhancing learning: a matter of style or approach? In: R. J. Sternberg, and L.F. Zhang (Eds) Perspectives on thinking, learning, and cognitive styles. Mahwah, NJ, Lawrence Erlbaum Associates: 73-102.

Campbell, R. J., Kyriakides, L., Muijs, R. D., \& Robinson, W. (2003). Differential Teacher Effectiveness: towards a model for research and teacher appraisal. Oxford Review of Education, 29(3), 347-362.

Carolan, J., \& Guinn, A. (2007). Differentiation: Lessons from Master Teachers. Educational Leadership, 64(5), 44-47. 
Centre for Comprehensive School Reform and Development (2007). A Teacher's guide to Differentiating Instruction, January, 2007. www.centerforcsri.org Retrieved March $1^{\text {st }} 2008$.

Claxton, G. (2007). Expanding young people's capacity to learn. British Journal of Educational Studies, 55(2), 115-134.

Coffield, F., Moseley, D., Hall, E., \& Ecclestone, K. (2004). Learning styles and pedagogy in post-16 learning: A systematic and critical review. London: Learning and Skills Research Centre, LSDA.

De Vaus, D. (2002). Analysing Social Science Data: 50 Key Problems in Data Analysis. London: Sage Publications.

DCSF, (2009a). Your child, your schools, our future: building a $21^{\text {st }}$ century schools system. London: Department for Children, School and Families.

DCSF (2009b). The Children's plan Two years on: a progress report. London:

Department for Children, School and Families.

DFE (2010). The importance of teaching: The schools White Paper 2010. London: Department for Education.

DfES (2004). Five Year Strategy for Children and Learners. London: Department for Education and Skills.

DfES (2006). Five Year Strategy for Children and Learners: Maintaining the Excellent Progress. London: Department for Education and Skills.

DfES (2007a). 2020 Vision-Report of the Teaching and Learning in 2020 Review Group. London: Department for Education and Skills.

DfES (2007b). Making Good Progress. How can we help every pupil to make good progress at School? London: Department for Education and Skills.

Dunn, R., Griggs, S.A., Olson, J., Beasley, M., \& Gorman, B.S. (1995). A metaanalytic validation of the Dunn and Dunn model of learning style preference. Journal of Educational Research, 88(6), 353-362.

Epstein, S. (1994). Integration of the cognitive and the psychodynamic unconscious. American Psychologist, 49(2), 709-724.

Epstein, S. (2004). Intuition from the perspective of cognitive-experiential self-theory. 5th Heidelberg Meeting on Judgment and Decision Processes 'Intuition in Judgment and Decision Making', University of Heidelberg, February 19-22, 2004.

Evans, C. (2004) Exploring the Relationship between Cognitive Style and Teaching. Educational Psychology, 24(4), 509 - 531. 
Evans, C., \& Cools, E. (2009). The use and understanding of style differences to enhance learning. Reflecting Education, 5, 1-18.

Evans, C., and Kozhevnikov, M. (in press). Styles of practice: How learning is affected by students' and teachers' perceptions and beliefs, conceptions and approaches to learning. Research Papers in Education.

Evans, C., \& Waring, M. (2006). Towards Inclusive Teacher Education: Sensitising Individuals to How They Learn. Educational Psychology (6), 499-518.

Evans, C., \& Waring, M. (2007). Using the CSI in Educational Settings. In: L.M. Lassen, L. Bostrum, \& H. H. Henrik Knoop, (Eds.) Laering og laeringsstile om unikke og faelles veje I paedagogikken, Denmark: Dansk Psykolgisk Forlag, 103 -122 .

Evans, C., \& Waring, M. (2008). Trainee teachers' cognitive styles and notions of differentiation. Education and Training, 50(2), 140-154.

Evans, C., \& Waring, M. (2009). The place of cognitive style in pedagogy: Realising potential in practice. In L. F. Zhang \& R. J. Sternberg (Eds), Perspectives on the nature of intellectual styles (pp. 169-208). New York: Springer.

Evans, C., \& Waring, M. (2011). Enhancing feedback practice: aA personal learning styles pedagogy approach. In S. Rayner \& E. Cools (Eds.), Style differences in cognition, learning and management: Theory, research and practice (pp. 188203). New York: Routledge.

Everest, C. (2003, February 18). Differentiation, the new monster in education. The Education Guardian.

Gopinathan, S., Tan, S., Yanping, F., Devi, L., Ramos, C., \& Chao, E. (2008). Transforming Teacher Education: Redefined professionals for $21^{\text {st }}$ century schools. The National Institute of Education, Singapore: Nanyang Technological University.

Grossman, P., Hammerness, K., \& McDonald, M. (2009). Redefining teaching, reimagining teacher education. Teachers and Teaching: theory and practice, 15(2), 273-289.

Hastings, S., \& Jenkins, S. (2005). Learning Styles. The Times Educational Supplement, $4^{\text {th }}$ November 2005

Hayes, J., \& Allinson, C. W. (1994). Cognitive style and its Relevance for Management Practice, British Journal of Management, 5(1), 53-71.

Hayes, J., \& Allison, C. W. (1998). Cognitive style and the theory and practice of individual and collective learning in organizations, Human Relations, 51(7), 847880 . 
Heffler, B. (2001). Individual learning style and the learning style inventory. Educational Studies, 27(3), 307-316.

Henderson, D. (2006). "Student teachers can't cram it all in", The Times Educational Supplement, $10^{\text {th }}$ February 2006.

Hodgkinson, G. P., \& Sadler-Smith, E. (2003). Complex or Unitary: A Critique and Empirical Reassessment of the Cognitive Style Index. Journal of Occupational and Organisational Psychology, 76(2), 243-268.

IRA. (2008). Status of Teacher Education in the Asia-Pacific Region; Executive Summary. Thailand: UNESCO:International Reading Association. Retrieved January 10 2011. Accessed from: http://www.unescobkk.org/education/teachereducation-and-training/stauts-of-teacher. .

James, M., \& McCormick, (2009). Teachers learning how to learn. Teaching and Teacher Education, 25(7), 973-982.

Kirton, M. J., \& DeCiantis, S. M. (1986). Cognitive style and personality: the Kirton adaption-innovation inventory and Catell's sixteen personality factor inventories, Personality and Individual Differences, 7(2), 141-146.

Kosnick, C., \& Beck, C. (2009). Priorities in teacher education: The 7 key elements of pre-service preparation. New York: Routledge.

Kozhevnikov, M. (2007). Cognitive Styles in the Context of Modern Psychology: toward an Integrated Framework of Cognitive Style. Psychological Bulletin, 133(3), 464-481.

Lawrence, M. V. M. (1997). Secondary school teachers and learning style preferences: Action or watching in the classroom? Educational Psychology, 17(1\&2), 157-170.

Lim, C. P., Cock, L., Lock, G., \& Brook, C. (Eds.) (2009). Innovation practices in pre-service teacher education: An Asia-Pacific Perspective. Rotterdam: Sense Publishers.

Loyens, S. M. M., \& Gijbels, D. (2008). Understanding the effects of constructivist learning environments: introducing a multi-dimensional approach. Instructional Science 36: 351-357.

Mason, J. (2009). Teaching as a disciplined enquiry. Teachers and Teaching:Theory and Practice, 15(2), 205-224.

Messick, S. (1984). The nature of cognitive styles: problems and promise in educational practice, Educational Psychologist, 19(2), 59-74.

Messick, S., (1996). Cognitive styles and learning. In E. De Corte, F. Weinert (Eds.), International encyclopaedia of developmental and instructional psychology, Oxford, Elsevier Science Ltd, 638-641. 
MOE. (2005). Framework for "Teach Less, Learn More" Recommendations. Ministry of Education Work Plan Seminar 2005. Retrieved Sep 14 ${ }^{\text {th }} 2008$. Accessed from: http://www.moe.gov.sg.

Mutton, T., Burn, K., \& Hagger, H. (2010). Making sense of learning to teach: learners in context, Research Papers in Education, 25(1), 73-91.

NERF. (2004-5). Bulletin Evidence for Teaching and Learning: Learning Styles should be handled with care. National Educational Research Forum, 7(2), 7.

Newby, M. (2005). A curriculum for 2020. Journal of Education for Teaching, 31 (4), 297-300.

NIE. (2009). TE21 A Teacher Education Model for the $21^{\text {st }}$ Century. Singapore: National Institute of Education.

NIE. (2010). Perspectives in Motivating Educators and Learners. Singapore: National Institute of Education.

Nielson, T. (2008). Implementation of learning styles at the teacher level. Education and Training, 50(2), 167-182.

NSIN. (2005). Research Matters: Learning Styles: help or hindrance? National School Improvement Network, No. 26 Institute of Education, University of London.

Nosal, C.S. (1990). Psychologiczne modele umyslu [Psychological models of mind] Warsaw, Poland. PWN.

O’Brien, T. (2000). "Providing inclusive differentiation", in Benton, P. and O'Brien, T. (Eds) Special Needs and the Beginning Teacher. London: Continuum.

O'Brien, T., \& Guiney, D. (2001). Differentiation in Teaching and Learning. London: Continuum.

Oaksford, L., \& Jones, L. (2001), Differentiated instruction abstract, Leon County Schools, Tallahassee, FL.

OECD. (2009). Creating effective teaching and learning environments: First results from TALIS. Retrieved 26 January 2010 from: http://www.oecd.org/document/54/0,3343,en_2649_39263231_42980662_1_1_1 $\underline{1,0}$

Pedrosa-de-Jesus, H., \& da Silva Lopes. (in press). The relationship between teaching and learning conceptions, preferred teaching approaches and questioning practices. Research Papers in Education.

Pettig, K. L. (2000). "On the road to differentiated practice". Educational Leadership, 5(1), 14-18. 
Poplin, M., \& Rivera, J. (2005). Merging social justice and accountability: educating qualified and effective teachers. Theory into Practice, 44(1), 280-312.

Riding, R. (2005). Individual Differences and Educational Performance. Educational Psychology, 25(6), 659-672.

Riding, R. \& Rayner, S. (1998). Cognitive styles and learning strategies: Understanding style differences in learning and behaviour. London: David Fulton.

Rosenfeld, M., \& Rosenfeld, S. (2008). Developing effective teacher beliefs about students: Do teachers' own individual learning differences (ILDs) make a difference? Educational Psychology, 28(3), 245- 272.

Sadler-Smith, E. (2008). Does Cognitive Styles Research Connect with Relevant Psychological Theory? In E. Cools, H. Van den Broeck, C. Evans, \& T. Redmond, T. (Eds.), Proceedings of the $13^{\text {th }}$ Annual Conference of the European Learning Styles Information Network, 23-25 June, 2008, Vlerick Leuven Gent Management School, Gent, Belgium, 437-456.

Sharp, J. G., Bowker, R., \& Byrne, J. (2008). VAK or VAK-ous? Towards the trivialisation of learning and the death of scholarship. Research Papers in Education, 23 (3), 293-314.

Sternberg, R. J., \& Grigorenko, E. L. (1997). Are Cognitive Styles Still In Style? American Psychologist, 52(7), 700-712.

Stringer, P. (2005). Interview with Frank Coffield: A question of style. The Psychologist, 18(6), 366-367.

TL2020RG (2006). 2020 Vision. Report of the Teaching and Learning in 2020 Review Group. Nottingham: DfES.

TLRP. (2008). New teachers as learners: a model of early professional development. Research Briefing No. 56. Teaching and Learning Research Project UK. $\begin{array}{lllll}\text { Retrieved } & 10 & \text { January } & 2009 & \text { from }\end{array}$ http://www.tlrp.org/dspace/retrieve/3714/56+Mcnally+final.pdf

Tomlinson, C. A. (2005). Differentiated Instruction as a way to achieve Equity and Excellence in Today's Schools, Building Inclusive Schools: a Search for Solutions. Conference Report Canadian Teachers' Federation Conference, November 17-19 ${ }^{\text {th }}$ 2005, Ottawa, Ontario, 19-21.

Tomlinson, C. A. (2000). Differentiation of instruction in the elementary grades. ERIC Digest. Champaign, IL:ERIC Clearinghouse on Eleemntary and Early Childhood Education. (ERC Document No. ED443572). Retrieved June 2007 http:??www.eric.ed.gov/ERICDocs/data/ericdocs2/content_storage_01/0000000b /80/2a/38/f4.pdf 
U.S. Department of Education (2002). No Child Left Behind: A desktop reference. Washington: U.S. Department of Education, Office of Elementary and Secondary Education.

Wang, A. H., Coleman, A. B., Coley, R. J., \& Phelps, R. P. (2003). Preparing Teachers Around the World. Princeton, NJ, Educational Testing Service. (www.ets.org/research/plc).

Westwood, P. (2005). "Adapting Curriculum and Instruction”, in K. Topping, \& S. Maloney (Eds.) The Routledge Falmer Reader in Inclusive Education. London: Routledge Falmer, 145-159.

Yates, G. C. R. (2000). Applying Learning Style Research In The Classroom: Some Cautions And The Way Ahead, 347-364. In R. J. Riding \& S. G. Rayner (Eds.), International Perspectives on Individual Differences, Volume 1 Cognitive Styles. Stamford: Ablex.

Younger, M., Brindley, S., Pedder, D, \& Hagger, H. (2004). Starting points: Student teachers' reasons for becoming teachers and their preconceptions of what this will mean. European Journal of Teacher Education, 27(3), 245-264.

Zhang, L. F. (in press). The developing field of intellectual styles: four recent endeavours. Learning and Individual Differences.

Zhang, L. F., \& Sternberg, R. J. (2006). The nature of intellectual styles. NJ: Lawrence Erlbaum.

Zhang, L. F., \& Sternberg, R. J. (2009). (Eds.) Perspectives on Intellectual Styles. New York: Springer. 
Table 1: Mean scores and Post-hoc Tukey results for 4 CSI groups

\begin{tabular}{|c|c|c|c|c|c|}
\hline Item & Description & $\mathrm{N}$ & Style & Means (SD) & Tukey \\
\hline \multirow[t]{4}{*}{ B5 } & I am most happy working on & 62 & 1 & $3.40(1.05)$ & $1 \& 4$ \\
\hline & several projects at the same time & 21 & 2 & $3.00(1.30)$ & \\
\hline & finding it easy to move from one & 23 & 3 & $3.52(1.08)$ & $3 \& 4$ \\
\hline & $\begin{array}{l}\text { project to another and completing } \\
\text { them all on time }\end{array}$ & 42 & 4 & $2.76(1.19)$ & \\
\hline \multirow[t]{4}{*}{ B6 } & I like inventing new ways to do & 62 & 1 & $2.65(1.04)$ & $1 \& 2,4$ \\
\hline & things, trying out new ideas, & 21 & 2 & $1.95(.80)$ & \\
\hline & developing new resources and & 23 & 3 & $2.52(.79)$ & \\
\hline & $\begin{array}{l}\text { approaching lessons from different } \\
\text { angles. }\end{array}$ & 42 & 4 & $2.02(.95)$ & \\
\hline \multirow[t]{4}{*}{ B7 } & I like to follow a clear set of & 62 & 1 & $1.82(.82)$ & $1 \& 2,4$ \\
\hline & logical procedures, analysing each & 21 & 2 & $2.42(.87)$ & \\
\hline & step as I go. & 23 & 3 & $2.30(.88)$ & \\
\hline & & 42 & 4 & $2.81(1.06)$ & \\
\hline \multirow[t]{4}{*}{ B8 } & I am happy to follow any rules and & 62 & 1 & $1.92(.89)$ & \\
\hline & procedures set for me & 21 & 2 & $2.52(1.03)$ & \\
\hline & & 23 & 3 & $2.30(1.02)$ & \\
\hline & & 42 & 4 & $2.33(1.20)$ & \\
\hline \multirow[t]{4}{*}{ B9 } & I like to try out new ideas and to & 62 & 1 & $3.23(.99)$ & $1 \& 4$ \\
\hline & take risks even if it means not & 21 & 2 & $2.61(.80)$ & \\
\hline & following the guidelines. & 23 & 3 & $2.87(.87)$ & \\
\hline & & 42 & 4 & $2.38(1.08)$ & \\
\hline \multirow[t]{4}{*}{ B10 } & In a new situation I like to take the & 62 & 1 & $2.63(.96)$ & $1 \& 2,4$ \\
\hline & initiative, being able to step in and & 21 & 2 & $1.9(1.09)$ & $2 \& 3$ \\
\hline & direct things where necessary. & 23 & 3 & $2.73(.77)$ & $3 \& 4$ \\
\hline & & 42 & 4 & $1.88(.78)$ & \\
\hline \multirow[t]{4}{*}{ B11 } & I prefer and am most effective & 62 & 1 & $2.68(1.02)$ & \\
\hline & when leading and directing a & 21 & 2 & $2.19(1.12)$ & \\
\hline & group. & 23 & 3 & $2.87(1.01)$ & \\
\hline & & 42 & 4 & $2.29(.94)$ & \\
\hline \multirow[t]{4}{*}{ B12 } & I am able to make decisions & 62 & 1 & $2.73(.85)$ & $1 \& 4$ \\
\hline & quickly and once I have made a & 21 & 2 & $2.43(1.08)$ & \\
\hline & decision I go with it. & 23 & 3 & $2.70(.97)$ & \\
\hline & & 42 & 4 & $2.14(.98)$ & \\
\hline \multirow[t]{4}{*}{ B14 } & I scan information quickly and & 62 & 1 & $2.87(.97)$ & $1 \& 4$ \\
\hline & react quickly to it. & 21 & 2 & $2.81(.93)$ & \\
\hline & & 23 & 3 & $2.83(.89)$ & $3 \& 4$ \\
\hline & & 42 & 4 & $2.19(.97)$ & \\
\hline \multirow[t]{4}{*}{ B15 } & I weigh up what I read very & 62 & 1 & $2.26(.75)$ & $1 \& 4$ \\
\hline & carefully before responding. & 21 & 2 & $2.38(.86)$ & \\
\hline & & 23 & 3 & $2.96(1.02)$ & \\
\hline & & 42 & 4 & $4.05(5.9)$ & \\
\hline \multirow[t]{4}{*}{$\mathrm{C} 1$} & It is important for me to have a & 62 & 1 & $1.47(.65)$ & $1 \& 4$ \\
\hline & clear outline which shows the & 21 & 2 & $1.71(1.06)$ & \\
\hline & course divided up into clear & 23 & 3 & $1.87(.87)$ & \\
\hline & sections and for a lecturer to say at & 42 & 4 & $1.95(.96)$ & \\
\hline
\end{tabular}


about to learn.

$\begin{array}{lllll}\text { C12 I prefer lessons where there is a } & 62 & 1 & 2.08(.80)\end{array}$

$\begin{array}{llll}\text { more informal atmosphere. } & 21 & 2 & 2.00(.95)\end{array}$

$23 \quad 3 \quad 1.91(.85)$

$424 \quad 4 \quad 1.69(.81)$

C13 I prefer lessons where the teaching $62 \quad 1 \quad 3.36(1.14)$ approach is not very structured and $21 \quad 2 \quad 2.71(1.27)$ where the teacher is prepared to go $23 \quad 3 \quad 3.39$ (1.07) off at tangents and explore ideas in $\quad 42 \quad 4 \quad 2.52(1.11$

$1 \& 4$ detail that are raised by the students. 
Table 2: Significant Learning Preference Differences between the four CSI Style groups

\begin{tabular}{llll}
\hline Item No. & $\mathrm{F}$ & $\mathrm{p}$ & Effect Size \\
B5 & 3.59 & .015 & .07 \\
B6 & 5.13 & .002 & .10 \\
B7 & 10.12 & .000 & .17 \\
B8 & 2.54 & .059 & .05 \\
B9 & 6.64 & .000 & .12 \\
B10 & 8.57 & .000 & .15 \\
B11 & 2.89 & .037 & .06 \\
B12 & 3.57 & .016 & .07 \\
B14 & 4.84 & .003 & .09 \\
B15 & 2.75 & .045 & .05 \\
C1 & 3.14 & .027 & .05 \\
C12 & 2.89 & .041 & .10 \\
C13 & 5.76 & .001 & .11
\end{tabular}


Table 3: Self-review checklist for trainees to consider their approaches to teaching

\begin{tabular}{|c|c|c|}
\hline (i) & Volume of material: & $\begin{array}{l}\text { What are the essential concepts to be delivered? How can } \\
\text { this material be organised in different ways? }\end{array}$ \\
\hline (ii) & Modes of presentation: & $\begin{array}{l}\text { What is the best way to present and design information in } \\
\text { relation to the required outcomes of the task? }\end{array}$ \\
\hline (iii) & $\begin{array}{l}\text { Pace, speed and number of transitions } \\
\text { between activities: }\end{array}$ & $\begin{array}{l}\text { What is the impact of pace on different types of learning } \\
\text { and for different learners? }\end{array}$ \\
\hline (iv) & $\begin{array}{l}\text { Design of learning sequences } \\
\text { (tangential vs sequential): }\end{array}$ & $\begin{array}{l}\text { What am I doing to encourage students to think both } \\
\text { creatively and rationally? }\end{array}$ \\
\hline (vi) & Nature of questioning (open vs closed): & $\begin{array}{l}\text { Am I using a range of question types to suit the needs of } \\
\text { the learning objectives? }\end{array}$ \\
\hline (vi) & Varying teaching styles: & $\begin{array}{l}\text { In my teaching, am I harnessing flexibility in styles (e.g. } \\
\text { impulsive and reflective and analytic and intuitive } \\
\text { cognitive styles)? }\end{array}$ \\
\hline (vii) & Self-discovery v directed teaching; & $\begin{array}{l}\text { Am I facilitating and directing learning in appropriate } \\
\text { ways? Am I encouraging both independence in learning as } \\
\text { well as inter-dependence? }\end{array}$ \\
\hline (viii) & Structure and organisation of lessons: & $\begin{array}{l}\text { Am I using structure and a lack of structure in lesson } \\
\text { design to support learning most effectively? }\end{array}$ \\
\hline (ix) & $\begin{array}{l}\text { Classroom design involving } \\
\text { organisation of seating: }\end{array}$ & $\begin{array}{l}\text { Am I using a variety of seating arrangements to support } \\
\text { specific learning goals? }\end{array}$ \\
\hline (x) & Management of power relations & $\begin{array}{l}\text { To what extent am I introducing choice for learners and } \\
\text { listening to student voice? }\end{array}$ \\
\hline (xi) & $\begin{array}{l}\text { Groupings (group, pair and individual } \\
\text { work): }\end{array}$ & $\begin{array}{l}\text { How am I using different groupings of students to support } \\
\text { the development of interpersonal skills? }\end{array}$ \\
\hline (xii) & Assessment: & $\begin{array}{l}\text { Am I using a range of assessment options that are aligned } \\
\text { to the learning objectives? Am I providing sufficient } \\
\text { choice in assessment? }\end{array}$ \\
\hline
\end{tabular}

